\title{
Análise dos benefícios da utilização de procedimentos baseados em desempenho e da utilização de aproximações de descida contínua na rota Galeão-Guarulhos
}

\author{
Daniel Alberto Pamplona ${ }^{1}$, João Luiz de Castro Fortes², Claudio Jorge Pinto Alves³
}

\begin{abstract}
Resumo: A introdução dos procedimentos PBN (Performance-Based Navigation) representa a busca pela otimização e melhor utilização do espaço aéreo e a sua implantação é considerada fundamental para os programas de modernização da navegação aérea em andamento em vários países, inclusive no Brasil. A implantação desse novo tipo de procedimento introduziu mudanças na operação das aeronaves, na inserção de novos procedimentos para controladores e pilotos e na introdução de sistemas de automação para suporte das operações aéreas e no solo. O objetivo desse artigo é analisar os benefícios da realização de Procedimentos de Navegação Baseados em Desempenho (PBN) e da utilização de Aproximações de Descida Contínua (CDA) na rota Galeão-Guarulhos. O estudo aplicou a simulação em tempo acelerado (fast-time) com o (Total Airspace and Airport Modeler) (TAAM) e considerou nove modelos diferentes de aeronaves. Utilizou como parâmetro de desempenho o combustível consumido. Os resultados do estudo mostraram que os benefícios da aplicação dessas técnicas variam conforme o modelo de aeronave.
\end{abstract}

Palavras-chave: PBN, CDA, TAAM, Desempenho, Performance-Based Navigation.

\begin{abstract}
The introduction of Performance-Based Navigation (PBN) procedures represents the search for optimization and better utilization of airspace, and its deployment is crucial for modernization programs of air navigation in progress in several countries, including Brazil. The implementation of this new type of procedure introduced changes in aircraft operation, the insertion of new procedures for air traffic controllers and pilots and the introduction of automation systems to support air operations. The aim of this paper is to analyze the benefits of performing PBN procedures and use of Continuous Descent Approaches (CDA) on the route Galeão-Guarulhos. The study applied fast-time simulation with the Total Airspace and Airport Modeler (TAAM) and considered nine different aircraft models. Fuel consumed is used as a performance parameter. Study results showed the benefits of applying these techniques vary according aircraft models..
\end{abstract}

Keywords: PBN, CDA, TAAM, Performance-Based Navigation.

1. INTRODUÇÃO

O aumento do emprego do avião como meio de transporte nas últimas décadas fez surgir a necessidade de uma melhor utilização do espaço aéreo. Uma das maneiras encontradas para a melhor utilização foi a introdução dos procedimentos PBN (Performance-Based Navigation), representando uma mudança da navegação baseada em sensores para uma navegação baseada em desempenho.

Aliado a esse aumento de necessidade, os sistemas de navegação aérea tornaram-se mais precisos, possibilitando uma maior acuracidade da trajetória de voo e permitindo uma melhor eficiência operacional, ao viabilizar uma trajetória de voo direta e precisa da localização da aeronave em relação à rota de voo planejada. Esse avanço permitiu as aeronaves voarem direto entre pontos sem terem a necessidade de dependerem de auxílios a navegação baseados no solo (NDB, VOR) e sim usando a navegação baseada em satélites (ICAO, 2013).

\footnotetext{
${ }^{1}$ Daniel Alberto Pamplona, Instituto Tecnológico de Aeronáutica, ITA (pamplonadefesa@gmail.com)

2 João Luiz de Castro Fortes, Instituto Tecnológico de Aeronáutica, ITA (jlfortes@gmail.com)

${ }^{3}$ Claudio Jorge Pinto Alves, Instituto Tecnológico de Aeronáutica, ITA. (claudioj@ita.br)
}

Manuscrito recebido em 28/10/2014 e aprovado para publicação em 22/04/2015.

Este artigo é parte de TRANSPORTES v. 23, n. 2, 2015. ISSN: 2237-1346 (online). DOI:10.14295/transportes.v23i2.862
O conceito PBN se refere aos requisitos de performance a serem aplicados a: rota de tráfego aéreo, procedimento por instrumento ou um espaço aéreo definido. Englobam o conceito os procedimentos RNAV (Area Navigation) e RNP (Required Navigation Performance) (Nolan, 2010). Os procedimentos RNAV e RNP são considerados como fatores fundamentais para a melhora na eficiência e capacidade do sistema de espaço aéreo. Sua introdução é considerada como fator fundamental para a implantação do programa NextGen nos Estados Unidos, SESAR na Europa e SIRIUS no Brasil. Com a introdução dos procedimentos RNP e aumento da confiabilidade na exatidão da localização, permitiu-se ao planejador do espaço aéreo o uso mais eficiente do espaço aéreo.

O objetivo do artigo é mensurar os benefícios da implantação do PBN no espaço aéreo, em particular na rota ligando os Aeroportos do Galeão e de Guarulhos, tendo como parâmetro de análise de eficiência o consumo de combustível. Para isso, utilizou-se a simulação em tempo acelerado (fast-time) com o software TAAM (Total Airspace and Airport Modeler). Para verificar se ocorreram diferenças de desempenho por modelo de aeronave a simulação comparou o gasto de combustível de nove diferentes tipos de aviões.

A contribuição científica do artigo é a de, através da utilização da simulação em tempo acelerado, comparar o consumo de combustível com a realização de procedimentos RNP, RNAV e Convencional e verificar qual que apresenta o melhor desempenho. Diferentemente de outros estudos, além de verificar o consumo durante o procedimento de aproximação, foram comparados os consumos durante 
Análise dos benefícios da utilização de procedimentos baseados em desempenho e

da utilização de aproximações de descida contínua na rota Galeão-Guarulhos

toda a rota verificando-se areal contribuição na economia com o uso de novos procedimentos. A análise não ficou restrita a apenas um único tipo de aeronave sendo estudados nove diferentes modelos, dos quais oito são aeronaves à reação e uma turbo-hélice.

Esse artigo está estruturado em sete seções, além desta introdutória. A segunda seção apresenta o conceito da Navegação Baseada em Desempenho (PBN), seu histórico, suas principais características atuais, especificações do sistema, erros do sistema de navegação e fatores de planejamento. A terceira seção apresenta os estudos sobre a mensuração dos benefícios da implantação do PBN no espaço aéreo. A quarta seção descreve a simulação em tempo acelerado e parâmetros de avaliação. A seção cinco descreve a metodologia de planejamento dos voos empregada, da escolha das aeronaves utilizadas e dos procedimentos de voo analisados. Na sexta seção são apresentados os resultados comparando os vários consumos de combustível por procedimento e aeronave. Na sétima seção são apresentadas as conclusões do estudo.

\section{NAVEGAÇÃO BASEADA EM DESEMPENHO}

Os avanços da navegação aérea sempre estiveram ligados com os avanços da aviação. Inicialmente, devido à falta de instrumentos de voo ou sistemas que auxiliassem na navegação, os voos comerciais estavam limitados a realizarem suas rotas durante o dia e em boas condições meteorológicas. Os avanços tecnológicos propiciaram a navegação aérea nas mais diversas condições meteorológicas e a qualquer hora do dia ou da noite.

Atualmente, com a popularização dos sistemas satelitais de navegação, e a necessidade de maior aproveitamento do espaço aéreo, encontra-se em progresso a mudança do conceito de auxílios à navegação baseados em sensores para o conceito de navegação baseada em performance (PBN).

\subsection{Histórico}

A primeira tentativa da Organização de Aviação Civil (OACI) de planejar os procedimentos RNAV ocorreu em 1998 com a primeira edição do Documento n 8168. Nesse manual foram definidos os desempenhos que eram necessários para a operação RNAV. Inicialmente, esse tipo de procedimento era considerado como meio para a realização de procedimentos em rota e não para aproximação ao pouso. Porém, devido à falta de especificações e necessidades operacionais ocorreu pouca implementação pela indústria aeronáutica (ICAO, 2013).

Em 2007 durante a 36 Assembleia da OACI, os Estados membros comprometeram-se com a implementação e desenvolvimento da navegação baseada em performance, refletindo em um esforço mundial e não mais regional, em adotar a navegação satelital na aviação. Esse esforço foi reiterado na $37^{\circ}$ Assembleia que ocorreu em 2010, com a proposição de melhorias e definições dos procedimentos RNAV e RNP (ICAO, 2013).

O Documento $n^{\circ} 9613$ continuou a ser editado e teve a sua quarta edição em 2013, onde é sugerido que não deverão ser desenvolvidos novos procedimentos RNAV, devendo os novos procedimentos a serem adotados do tipo RNP baseados em satélites. A tendência é que os novos procedimentos RNP deverão abranger todas as fases do voo com o objetivo de maximizar os benefícios e minimizar os custos aos operadores (ICAO, 2013).

\subsection{Aspectos fundamentais}

O PBN pode ser definido como sendo uma rota ou procedimento cuja execução requer que o conjunto de sistemas da aeronave, qualificação da tripulação e sistemas de gerenciamento de tráfego aéreo atendam as especificações expressas em termos de acuracidade, integridade, disponibilidade e continuidade. O conceito é formado pelos procedimentos RNAV e RNP associados a um determinado nível de precisão para cada tipo de operação (CHANDRA; GRAYHEM; BUTCHIBABU, 2012).

Um dos objetivos originais do PBN é o de permitir as aeronaves utilizarem qualquer auxílio disponível para a navegação ao invés de ficar dependente de um único auxílio. Os auxílios à navegação transmitem informações de posição. Essas informações são recebidas pelos sensores a bordo das aeronaves e são transformadas em informação pelos sistemas de navegação das aeronaves.

Os auxílios baseados em solo que são utilizados na navegação PBN são o DME e o VOR. O NDB não é considerado uma fonte de posicionamento para o PBN. Os auxílios baseados no espaço são os sistemas de navegação satelital global ou (Global Navigation Satelite System) (GNSS). Atualmente, as constelações GNSS em operação são: GPS (EUA) e GLONASS (Rússia). Estão ainda em desenvolvimento as constelações Galileo (Europa), Beidou (China) e QZSS (Japão).

O sistema RNP é um sistema RNAV que permite o monitoramento a bordo e o alerta. O sistema deve ter a capacidade de seguir um caminho designado, devendo ser capaz ainda, de realizar trajetórias em curva. Em procedimentos que requeiram perfis verticais, devem ocorrer orientações verticais, indicação de ângulos verticais e limites de altitude definidos. A principal diferença entre a realização de um procedimento RNP e RNAV é a capacidade de monitoramento do desempenho realizado dentro da aeronave e os alertas que são emitidos quando da não conformidade com os pré-requisitos de segurança estabelecidos (ICAO, 2013).

Os procedimentos RNAV e RNP para a sua execução variam desde sistemas baseados em um único sensor a aqueles com vários tipos de sensores de navegação. Os sistemas de navegação em alguns procedimentos devem estar conectados a outros sistemas, como (auto-throttle) e o piloto-automático / diretor de voo, permitindo uma operação mais automatizada. A Figura 1 mostra uma configuração básica, onde o sistema de navegação está ligado a um único sensor e uma configuração complexa com vários sensores e aviônicos (ICAO, 2013).

\subsection{Especificações dos sistemas PBN embarcados e erros de navegação}

ICAO (2013) especifica que a aeronave voando os procedimentos RNAV ou RNP tenha os seus sistemas de navegação definidos em termos de acuracidade, integridade, disponibilidade e continuidade necessárias para a execução do procedimento específico.

- Acuracidade é definida como sendo o requisito de manter o posicionamento da aeronave em um raio de uma vez (1x) RNP por 95\% do tempo. Representa o 

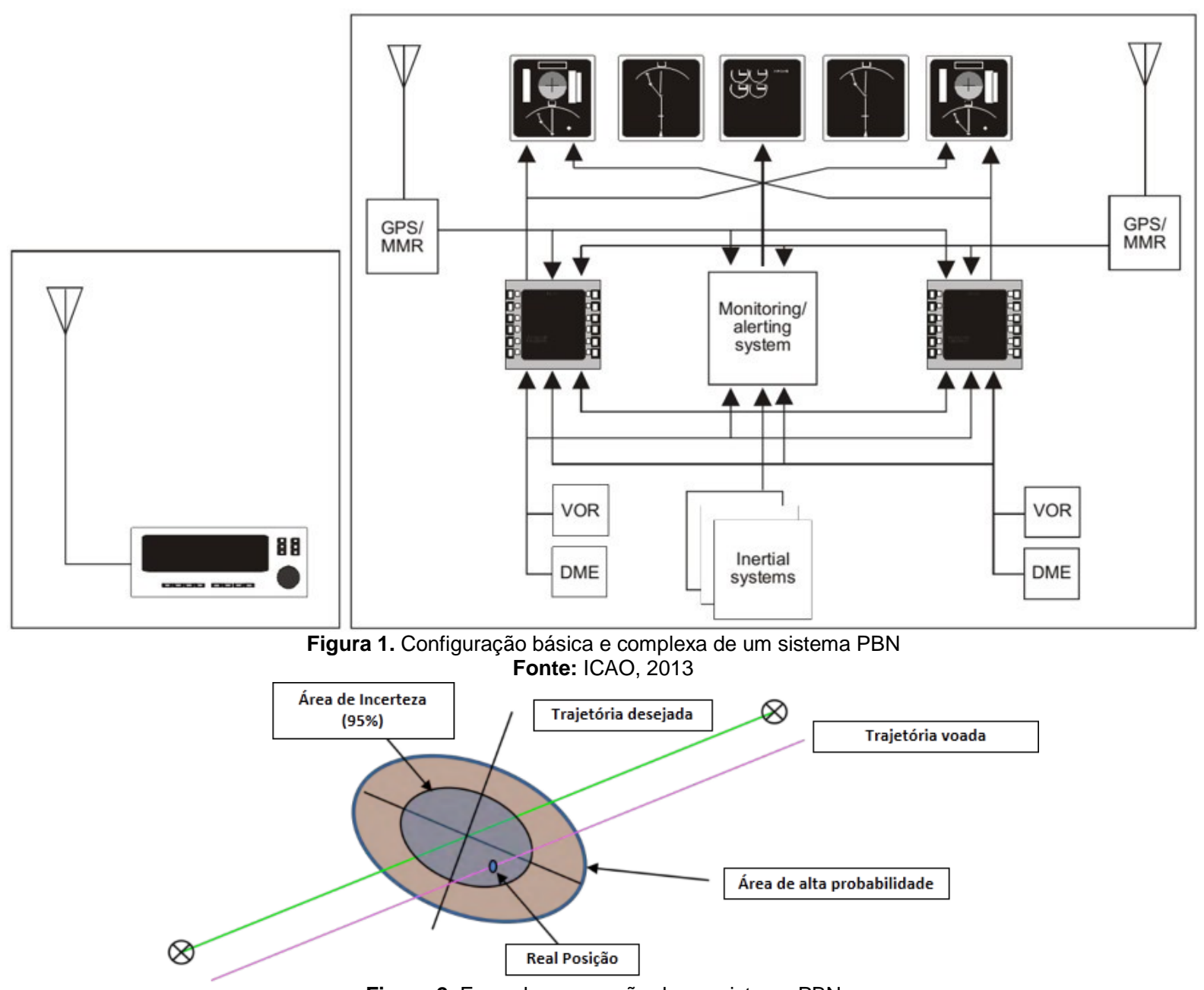

Figura 2. Erros de navegação de um sistema PBN Fonte: Adaptado de ICAO, 2013

grau de exatidão que a posição indicada é a posição atual.

- Integridade é definida como sendo o requisito de manter o posicionamento da aeronave em um raio de duas vezes (2x) RNP por 99,999\% do tempo.

- Disponibilidade é definida como sendo a probabilidade, usando modelos de risco, que o sistema de navegação (GPS, DME, VOR) utilizado para prover a acuracidade e a integridade da navegação estará presente durante a operação da aeronave.

- Continuidade é definida como sendo a probabilidade, usando modelos de risco, que o sistema de gerenciamento da navegação a bordo (FMS ou outro sistema) irá prover a acuracidade e a integridade durante a operação da aeronave.

Os sistemas de navegação RNAV e RNP possuem os mesmos tipos de erros de navegação. Os sistemas PBN utilizam a navegação em duas dimensões, baseando-se a sua posição em latitude e longitude. Ao ser estimada uma posição de destino, o sistema navega por uma rota definida com um determinado grau de acuracidade, conforme mostra a Figura 2.

O erro total da navegação, que deve ser previsto durante o planejamento e execução de um procedimento PBN, é a soma de três erros de navegação, vide Figura 3.

A linha preta representa o caminho desejado. É o caminho planejado pelo piloto para atingir o seu objetivo. $\mathrm{O}$ sistema de navegação irá computar uma réplica do caminho desejado, que será o caminho definido representado na linha vermelha, e o Erro de definição de caminho ou (Path Definition Error) (PDE) é a diferença de distância entre os dois caminhos. Esse erro, geralmente é o menor dos erros e muitas das vezes não é encontrado quando o sistema de navegação usa o mesmo sistema de coordenada que o do caminho desejado (ICAO, 2013).

O sistema de navegação da aeronave computa a localização para a aeronave, a posição estimada e busca manter a posição no caminho definido, qualquer erro encontrado será o Erro de orientação do caminho ou (Path Steering Error) (PSE) que é resultado da sensibilidade dos sistemas de controle de voo. Este erro é dependente do tipo de controle e do modo de operação (ICAO, 2013).

O último erro é a diferença entre a posição estimada e a verdadeira posição da aeronave. É definido como Erro de estimação da posição ou (Position Estimation Error) (PEE). Esse erro é dependente dos sensores da aeronave, da combinação das medidas e da dinâmica do voo. O Erro Total do Sistema ou (Total System Error) (TSE) é a soma de todos os erros e forma a base para a estimativa e monitoramento da posição e o ciclo de R95 indica que o erro total será menor que o raio do círculo 95\% das vezes (ICAO, 2013).

A navegação do sistema ocorre ao longo da rota desejada, existindo uma área de incerteza ao redor do posicionamento da aeronave, onde estará a verdadeira posição da aeronave, conforme Figura 4. A área mais escura representa que existe a probabilidade de $95 \%$ de nela estar contida a 
Análise dos benefícios da utilização de procedimentos baseados em desempenho e

da utilização de aproximações de descida contínua na rota Galeão-Guarulhos

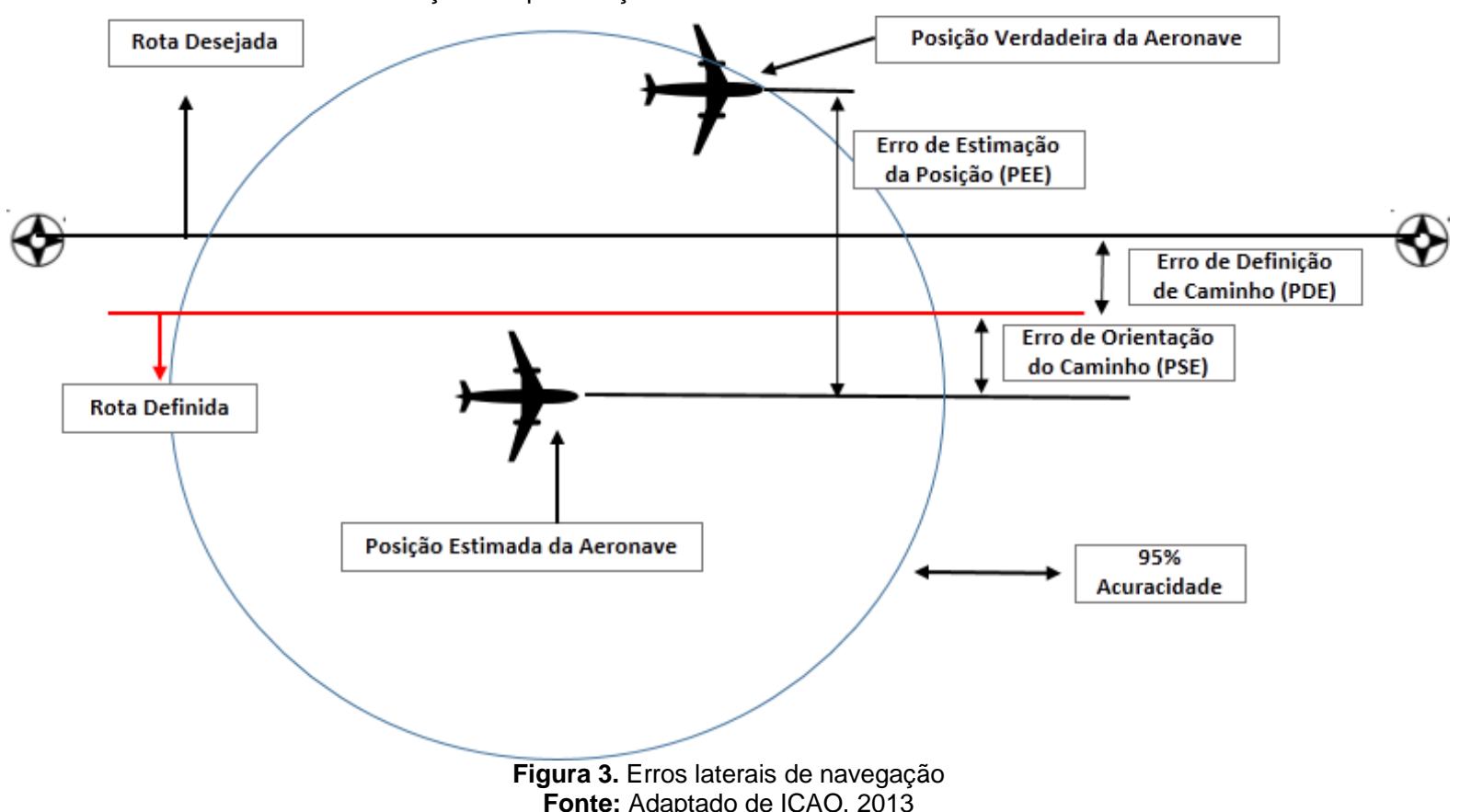

Fonte: Adaptado de ICAO, 2013

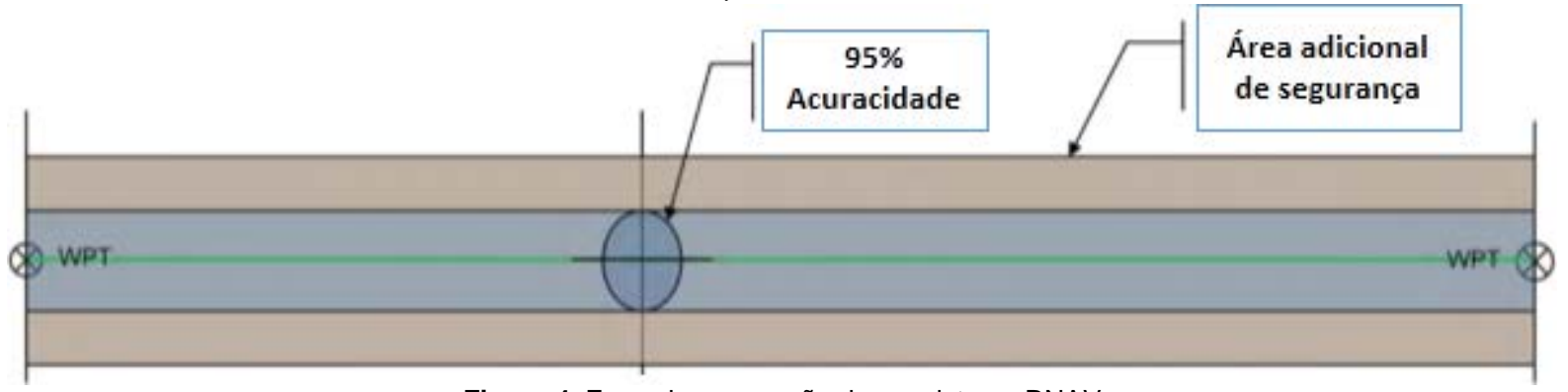

Figura 4. Erros de navegação de um sistema RNAV

Fonte: Adaptado de ICAO, 2013

aeronave. Essa probabilidade é utilizada para definir a acuracidade do equipamento de navegação. A parte mais clara representa uma maior probabilidade de estar a verdadeira posição da aeronave, caracterizando uma integridade de 99,999\% dos sistemas de navegação PBN. Os planejadores de rotas aéreas quando da confecção de procedimentos RNAV baseiam-se na probabilidade de $95 \%$ com a adição de uma zona de segurança, levando-se em conta várias combinações de sensores e certas condições de falha. (ICAO, 2013).

Na construção de rotas RNP, o planejador utiliza um parâmetro chamado de Valor RNP. Ao definir o valor RNP em milhas náuticas, o planejador escolhe a largura das áreas de proteção durante o caminho desejado, conforme Figura 5. A escolha do valor RNP define a integridade e continuidade a ser realizada durante os procedimentos pelos sistemas de navegação e controle embarcados. Com isso, abandona-se a dependência do sensor para a realização do procedimento e adota-se a performance realizada pelo sistema de navegação e controle da aeronave. Além disso, alertas devem ser emitidos à tripulação, caso os parâmetros não possam ser mantidos (ICAO, 2013).

A precisão na navegação permite ao planejador aéreo ampliar o uso do espaço aéreo e em uma região onde antes só era possível a disponibilização de uma aerovia devido à distância regulamentar baseada no desempenho do sensor, podem ser inseridas mais aerovias.

\subsection{Planejamento de rotas $\mathrm{PBN}$}

Através da utilização de novas técnicas oriundas do PBN, o planejador dispõe de vários meios para a melhor utilização do espaço aéreo.

\subsubsection{Curvas com raios fixos e fly-by}

A curva com raios fixos apresenta-se em duas formas: tipo rádio fixo e tipo raio fixo. A tipo rádio fixo é o tipo de curva que deve ser usada quando existe a necessidade de ser seguido um caminho específico em uma área de terminal ou procedimento de aproximação, devendo manter o nível de acuracidade que é encontrado nos segmentos em linha reta, conforme demonstra a Figura 6. O tipo raio fixo possui os mesmos requisitos sendo utilizada durante procedimentos em rota. Os procedimentos RNP devem manter o mesmo espaçamento entre rotas seja em linha reta ou em curva, não ocorrendo necessidade de aumentar o espaçamento nas curvas. Essa característica permite o planejamento de procedimentos em rotas com várias elevações topográficas ou evitar o ruído aeronáutico em determinadas áreas (ICAO, 2013).

Para realizar curvas fly-by, os sistemas de navegação RNAV e RNP utilizam as seguintes informações: velocidade da aeronave, ângulo de inclinação, vento, mudança de ângulo na rota e com elas calcula a trajetória de voo, conforme Figura 7. Devido diferenças no desempenho de cada 

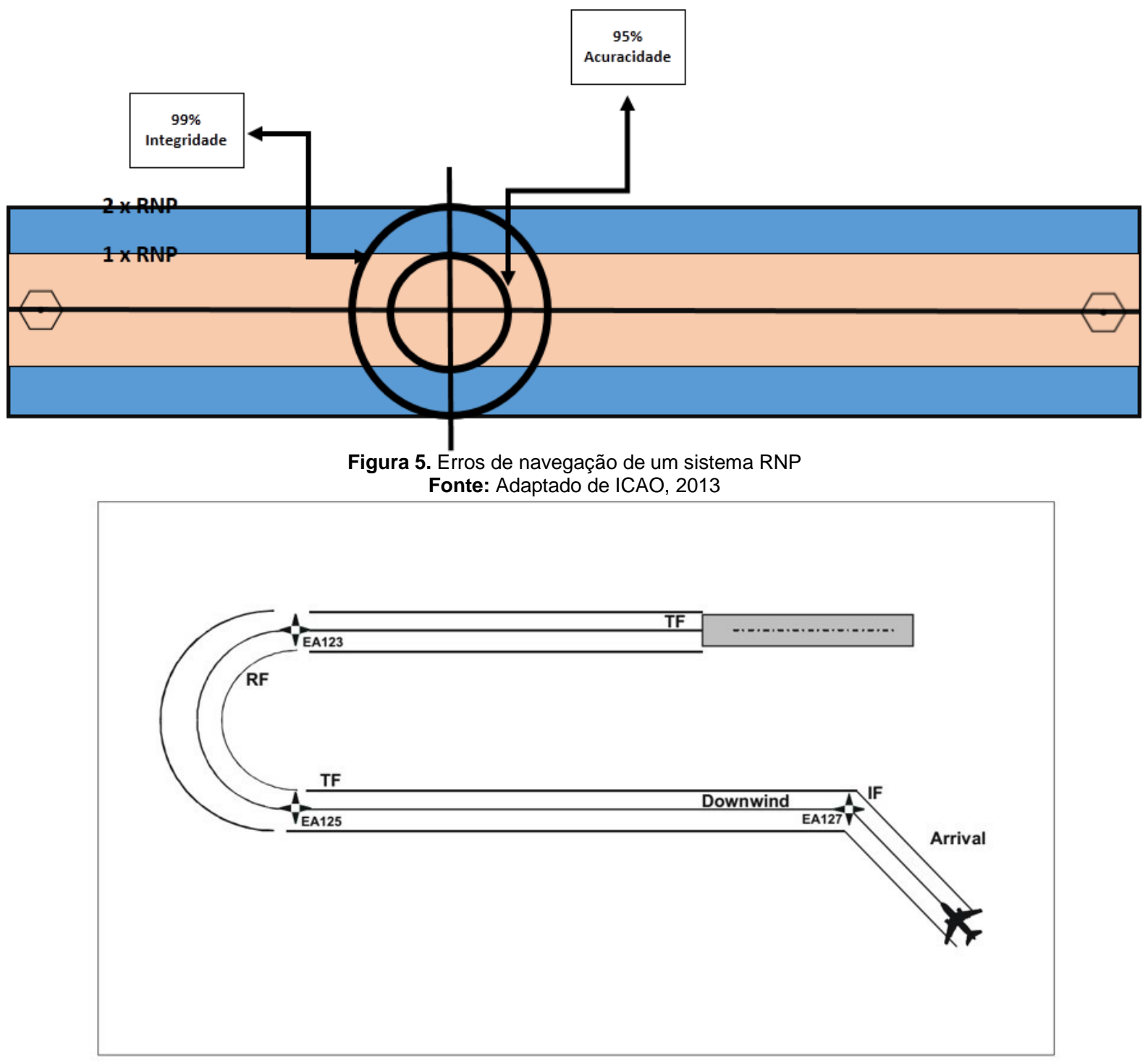

Figura 6. Curva do tipo raio fixo Fonte: ICAO, 2013

aeronave e devido condições locais como vento e velocidade da aeronave, o ponto de início da curva pode variar (ICAO, 2013).

\subsubsection{Rotas paralelas}

Os sistemas de navegação RNAV e RNP permitem que as aeronaves voem paralelamente uma rota selecionada, permitindo possíveis desvios de rota (mau tempo ou ultrapassagem de aeronave) sem comprometer a segurança e gerar invasão de outras aerovias, conforme mostra a Figura 8.

\subsubsection{Procedimentos abertos e Procedimentos fechados}

Com a utilização do conceito PBN é possível o desenvolvimento de procedimentos abertos e fechados. Os procedimentos abertos são construídos até um ponto perto da pista onde, a partir dele, a aeronave é vetorada pelo controle de tráfego aéreo até a aproximação final para pouso. Como consequência, o sistema RNAV só é capaz de calcular o regime de descida até o ponto final do procedimento e um regime de descida contínua não é possível a partir desse ponto, devido não se pode prever o comportamento do controle de tráfego aéreo, conforme Figura 9.
Os procedimentos fechados são construídos até o ponto de aproximação final com a utilização de um procedimento para pouso associado, geralmente a um ILS. Esse tipo de procedimento permite o planejamento do regime de descida até o toque na pista, conforme Figura 10. Para realizar essas funções, os sistemas de navegação PBN devem ser definidos em termos de acuracidade, integridade e disponibilidade, funções essas baseadas nos erros de navegação.

A implantação desse novo tipo de navegação, principalmente para a realização de procedimentos RNP, trará custos às empresas aéreas, que necessitarão modernizar as suas frotas e treinar as suas tripulações. Em um ambiente competitivo, mensurar os benefícios da utilização do PBN mostra-se de grande importância.

\section{ESTUDOS SOBRE A MENSURAÇÃO DOS BENEFÍCIOS DA IMPLANTAÇÃO DO PBN NO ESPAÇO AÉREO}

Por ser um tópico em desenvolvimento, a literatura abordando a quantificação dos benefícios da utilização dos 


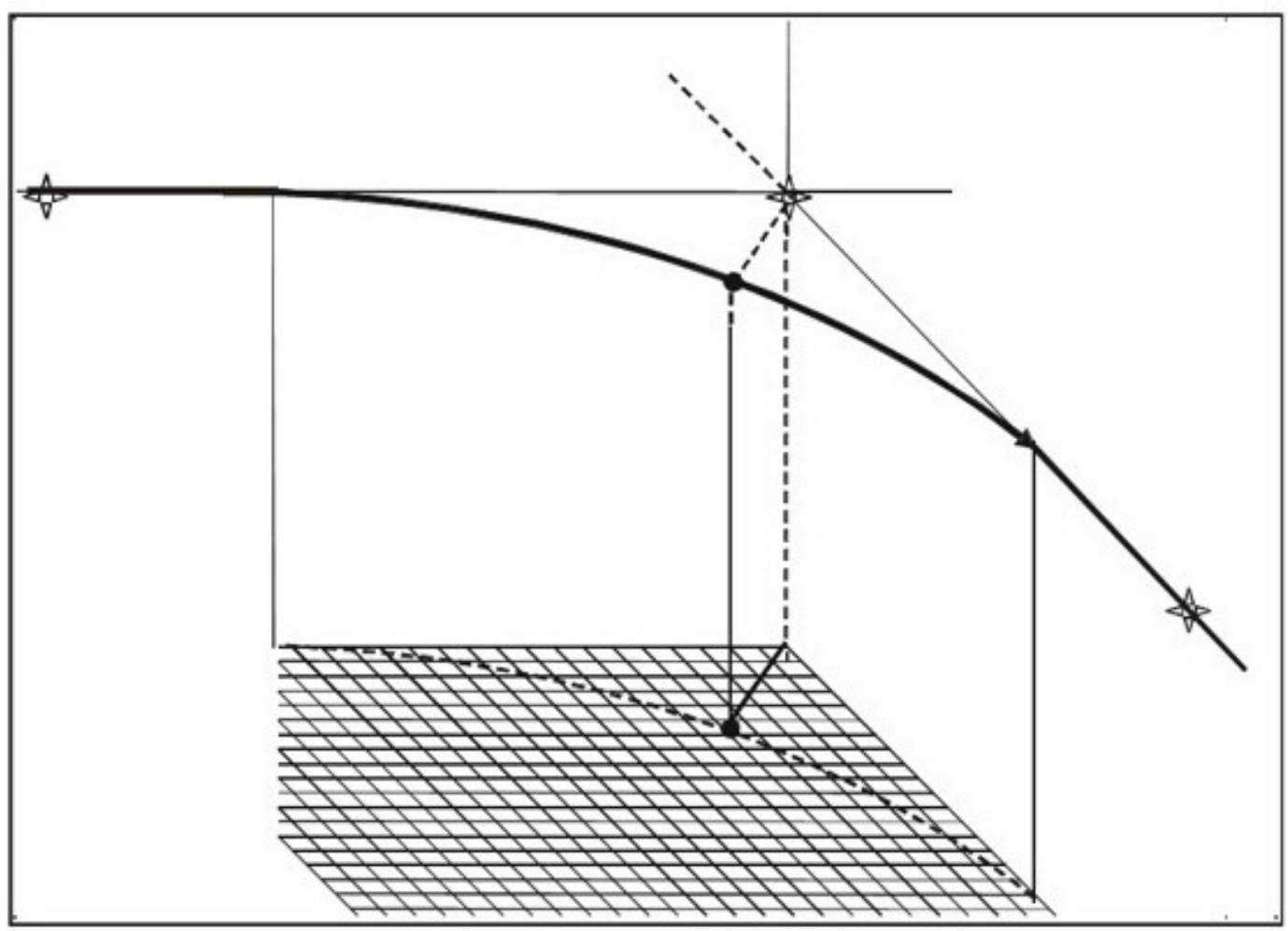

Figura 7. Curva Fly-by

Fonte: ICAO, 2013

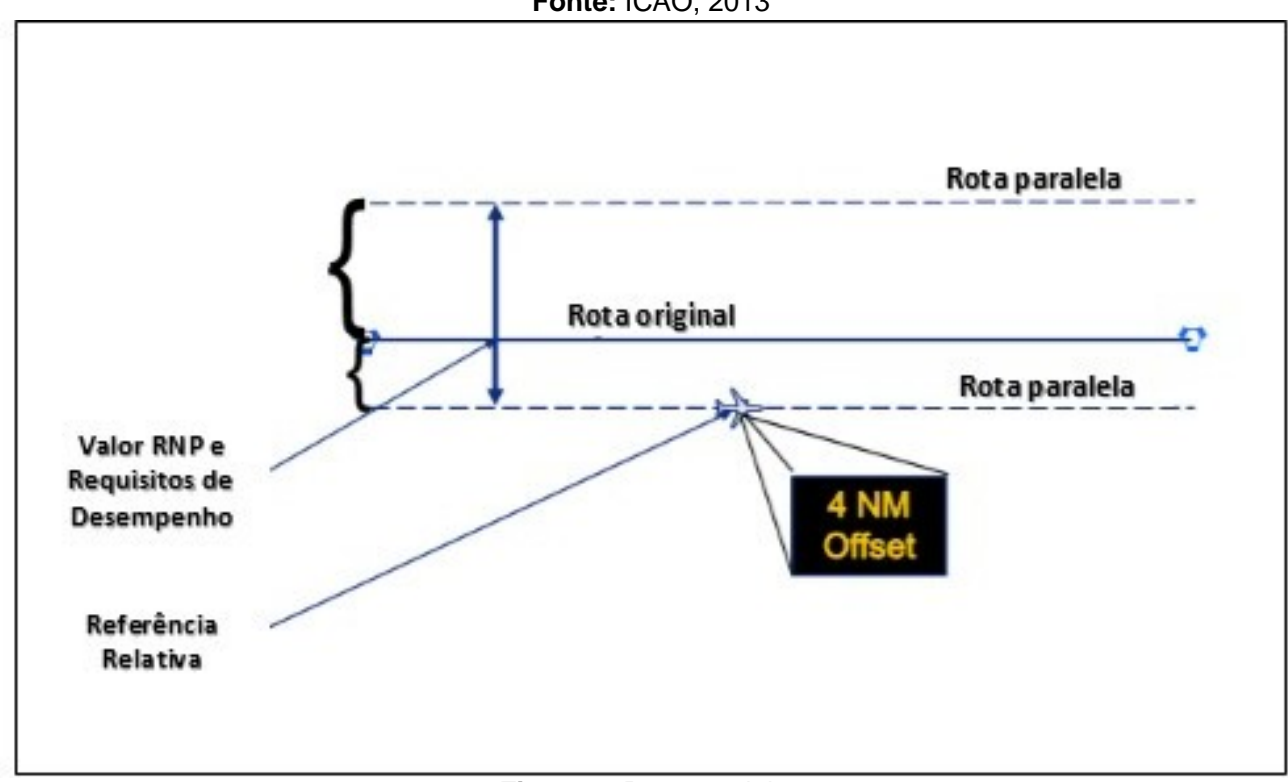

Figura 8. Rota paralelas

Fonte: Adaptado de ICAO, 2013

procedimentos PBN é incipiente. Em 2005, Sprong et al. analisam a melhora na eficiência de voo com a introdução dos procedimentos RNAV no Aeroporto Hartsfield-Jackson na cidade de Atlanta. Utilizaram os dados radar e modelagem em simulador, sendo que foram analisados apenas os procedimentos de saída (SID).

Sprong (2005), através de técnicas estatísticas, faz a comparação entre procedimentos RNAV e Convencional na chegada (STAR) do Aeroporto de Las Vegas. Utilizou como métrica para análise: tempo de voo, altitude e distância. O autor verificou no estudo os ganhos advindos da utilização dos procedimentos RNAV. Sprong (2007) analisou os procedimentos RNAV STAR em regime de descida contínua através da utilização dos dados radar do Aeroporto Internacional Sky Harbour em Phoenix. Os resultados mostraram uma redução de 38\% no tempo de voo e economia anual de consumo de combustível na ordem de 500 mil dólares.

Muller, Uday e Marais (2011), utilizando o aeroporto de Seattle-Tacoma, fizeram uma análise quantitativa dos benefícios RNAV e RNP. Os resultados indicaram ganhos na ordem de $40 \%$ nos procedimentos de aproximação. Para os autores, os ganhos só são mantidos quando as trajetórias otimizadas são realizadas.

Esse estudo se distingue por não se limitar a análise de apenas um tipo de procedimento mas por considerar todos os procedimentos de voo (SID, Rota, STAR e IAC). O estudo destaca-se ainda por considerar vários modelos de aeronaves e comparar os respectivos desempenhos. Foi utilizada a simulação em tempo acelerado como ferramenta para a realização do estudo.

\section{SIMULAÇÃO EM TEMPO ACELERADO E PARÂMETROS DE AVALIAÇÃO}

A simulação por computadores tem sido empregada desde 1950. A sua utilização se baseia no conceito de que uma abordagem experimental ou com teoria dos jogos pode ser válida para dar apoio ao tomador de decisão. A ideia é 


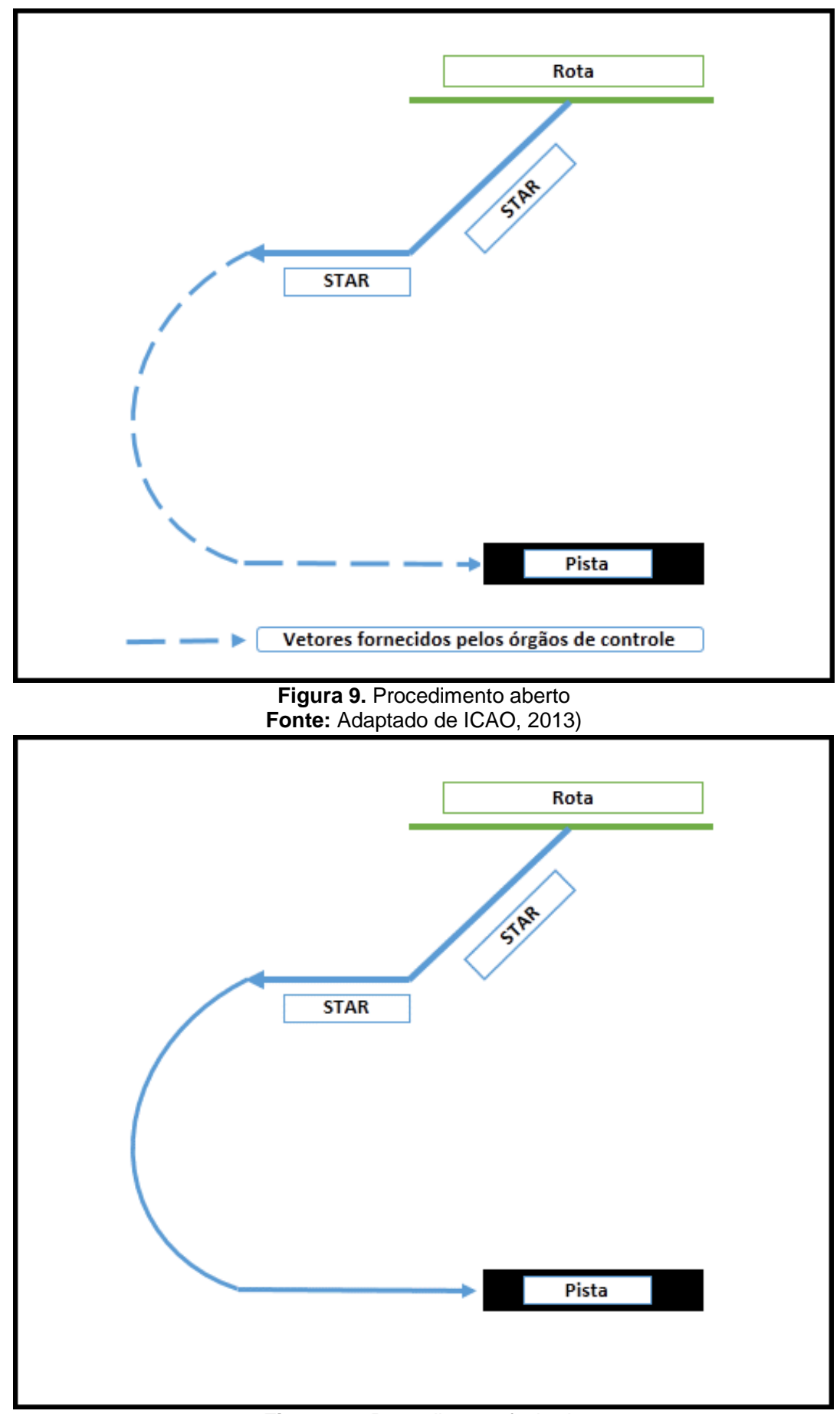

Figura 10. Procedimento fechado

Fonte: Adaptado de ICAO, 2013

poder experimentar uma política ou uma nova tarefa antes de ser implantada na vida real (PIDD, 1994).

A simulação segundo Banks (1998) pode ser definida como a imitação da operação de um processo ou de um sistema do mundo real sobre o tempo. Os modelos surgem como representações de um sistema real. O nível de representação da realidade, ou seja, o quanto acurado com o que é. O modelo está intimamente ligado ao nível das perguntas que se pretende responder. Quando o modelo é uma representação válida de um sistema, importantes informações podem ser obtidas sobre a dinâmica e o desempenho de um sistema.

A simulação aparece em contraste à abordagem analítica da solução de um problema. Em um modelo analítico, o modelo é expresso como um conjunto de equações que descrevem como o estado do sistema muda com o tempo. O conjunto de equações é resolvido com métodos matemáticos padronizados, seja através de álgebra ou cálculo, para determinar a situação em um tempo específico (WHITE e INGALLS, 2009).

A modelagem baseada em computador é um processo de simplificação e abstração no qual o modelador busca isolar os fatores nos quais ele acredita serem cruciais na operação do sistema a ser modelado. Esse processo de abstração depende dos dados e informações do sistema e de quais os objetivos perseguidos com a simulação (PIDD, 1994).

O gerenciamento do tráfego aéreo utiliza a simulação para verificar e testar conceitos e aplicações. A possibilidade de aceleração temporal (fast-time) da ferramenta de si- 


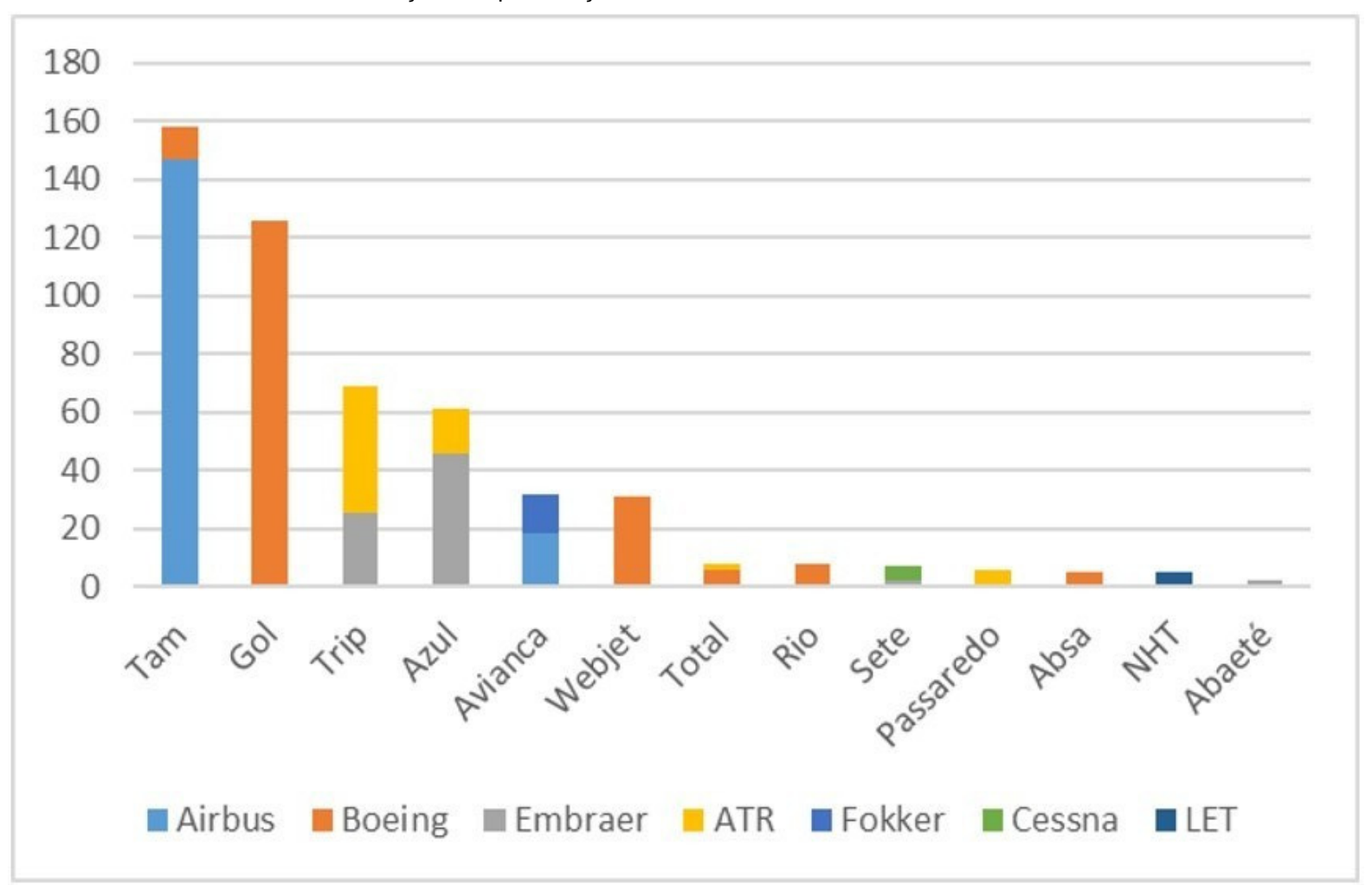

Figura 11. Frota e tipo de aeronaves das empresas brasileiras

Fonte: Adaptado de ANAC, 2013

mulação facilita a avaliação de vários conceitos, procedimentos e infraestruturas dentro de um curto período de tempo.

Novos procedimentos operacionais e conceitos de sistemas podem ser avaliados de forma rápida em termos de benefícios, de modo que a maioria dos novos conceitos operacionais possam ser selecionados para uma avaliação mais aprofundada na fase de concepção dos projetos. Os óbices podem ser identificados numa fase precoce, o que permite que o projeto seja melhorado antes da realização do projeto, evitando assim gastos elevados e desnecessários.

Através da simulação em tempo acelerado (fast-time) e utilizando o programa Total Airspace and Airport Modeler (TAAM), foram simulados, de forma individual, sem a interação das aeronaves em conjunto no espaço aéreo, as diferenças operacionais quando uma aeronave voa utilizando procedimentos PBN e procedimentos convencionais. O parâmetro operacional utilizado para comparação foi o consumo de combustível.

\section{PLANEJAMENTO dAS ROTAS E SIMULAÇÃO}

Para a seleção dos procedimentos a serem verificados, primeiramente foi realizado o planejamento da rota a ser utilizada nesse artigo. Cada voo simulado é composto de um somatório de procedimentos: decolagem, procedimento de saída (SID), voo em rota por aerovia, procedimento de chegada (STAR), procedimento de aproximação por instrumento (IAC) e pouso. A construção da simulação levou em conta que a aeronave só poderia voar, em toda a rota, um só tipo de procedimento PBN (RNAV ou RNP) ou Convencional (CNV), significando que a SID, STAR e IAC deveriam ser exclusivamente de um desses tipos. Os procedimentos utilizados foram os vigentes em dezembro de 2013 e foram fornecidos pelo Departamento de Controle do Espaço Aéreo (DECEA), órgão do Comando da Aeronáutica responsável em administrar e controlar o Espaço Aéreo Brasileiro, conforme Tabela2.

Para a escolha dos modelos de aeronaves a serem simulados, foi levado em consideração a frota das empresas aéreas brasileiras, segundo ANAC (2013). As aeronaves da fabricante Boeing representavam 36,10\%, da Airbus 31,85\% e da Embraer 14,48\%. A distribuição de aeronaves por operador e fabricante no ano de 2012 é representada na Figura 11.

As aeronaves utilizadas nesse estudo foram as empregadas pelas empresas brasileiras em voos domésticos. São divididas em aeronaves a reação e s a hélice, conforme Tabela 1 .

Tabela 1. Aeronaves utilizadas

\begin{tabular}{|c|c|}
\hline Aeronave a reação & Aeronave a hélice \\
\hline $\begin{array}{l}\text { A-319; A-320; A-321; } \quad \text { B-733; B- } \\
\text { 737; B-738;F-100; EMB-145; EMB-190 }\end{array}$ & ATR-72 \\
\hline
\end{tabular}

Fonte: Próprio autor

As cabeceiras utilizadas para pouso e decolagem foram as predominantes em cada aeroporto tendo como base o estudo da McKinsey (2010). As aeronaves decolaram utilizando a cabeceira 15 do Aeroporto do Galeão e pousaram na cabeceira 09R do Aeroporto de Guarulhos. A altitude de

Tabela 2. Procedimentos utilizados

\begin{tabular}{lllllll}
\hline Procedimento & Decolagem & SID & Aerovia & Star & IAC & Pouso \\
\hline PBN & $10 / 15$ & RNAV UGROK 1A & UZ 10 & RNAV ANSUG 1A & RNP X & 09R \\
PBN & $10 / 15$ & RNAV UGROK 1A & UZ 10 & RNAV ANSUG 1A & RNAV Y & 09R \\
Convencional & $10 / 15$ & UGROK 1B & Z10/W2 & ANSUG 1B & ILS T & 09R \\
\hline \multicolumn{7}{r}{ Fonte: Próprio autor } \\
\end{tabular}




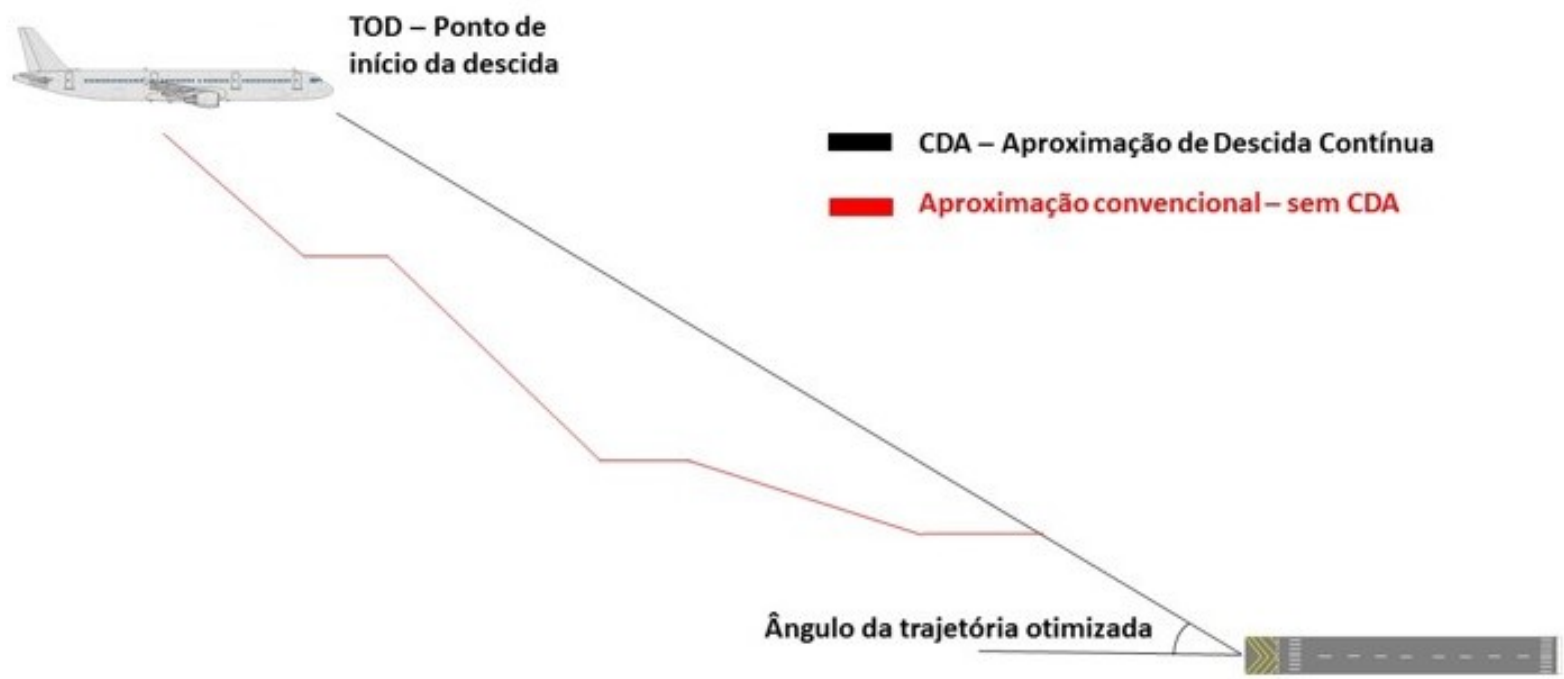

Figura 12. Aproximação de Descida Contínua e Aproximação Convencional Fonte: Próprio autor

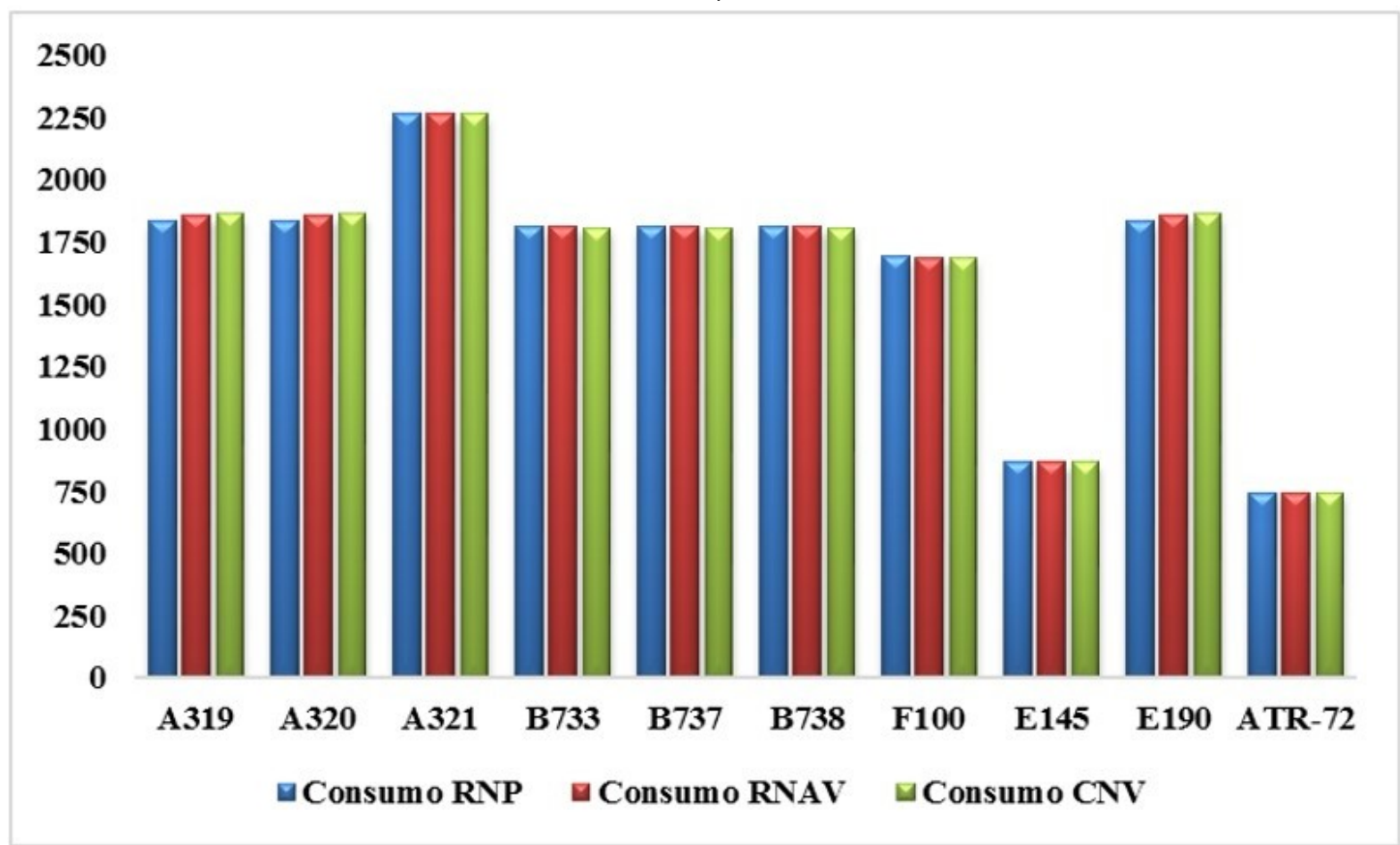

Figura 12. Consumo total da rota em quilos por procedimento sem CDA Fonte: Próprio autor

cruzeiro compreendeu 28.000 pés para as aeronaves a reação e 18.000 pés para as aeronaves a hélice. Buscando uma maior utilização e eficiência dos procedimentos, foram simulados voos com o emprego do conceito de Aproximações de Descida Contínua (CDA).

A utilização da técnica CDA é definida como sendo uma técnica de operação da aeronave, auxiliada por um espaço aéreo apropriado, confecção da carta de procedimento e autorizações do controle de tráfego aéreo, que permitem a execução de um perfil de voo otimizado às características operacionais da aeronave, em um regime de baixa utilização dos motores e, quando possível, em configurações de baixo arrasto (flap, slat, slot e trem de pouso). Como consequência direta, ocorre a redução no consumo de combustível e de emissões durante a descida. O perfil vertical ótimo deve ser o mais contínuo possível, dificilmente devendo ocorrer nivelamentos de voo, apenas em situações de desaceleração da aeronave, configuração para pouso e captura de procedimentos de guiamento de pouso, conforme Figura 12 (ICAO, 2010).

O ângulo da trajetória vertical otimizada pode variar em função do tipo de aeronave, seu peso real, vento, temperatura do ar, pressão atmosférica, condições de gelo em rota e outras variáveis dinâmicas. A realização da CDA será o mais benéfica a medida que a aeronave consegue manter o seu voo de cruzeiro por maior tempo até que seja atingido o ponto ideal de descida (ICAO, 2010).

Em uma aproximação convencional, a aeronave inicia a sua descida e é obrigada a nivelar seguindo as orientações do tráfego aéreo. Para isso, a aeronave deve iniciar a sua descida antecipadamente quando comparado com a descida CDA. Durante os períodos em que ocorre o voo nivelado, a aeronave é obrigada a aumentar a potência para manter a altitude e velocidade constantes, como consequência ocorre o aumento do consumo de combustível. Quando a 


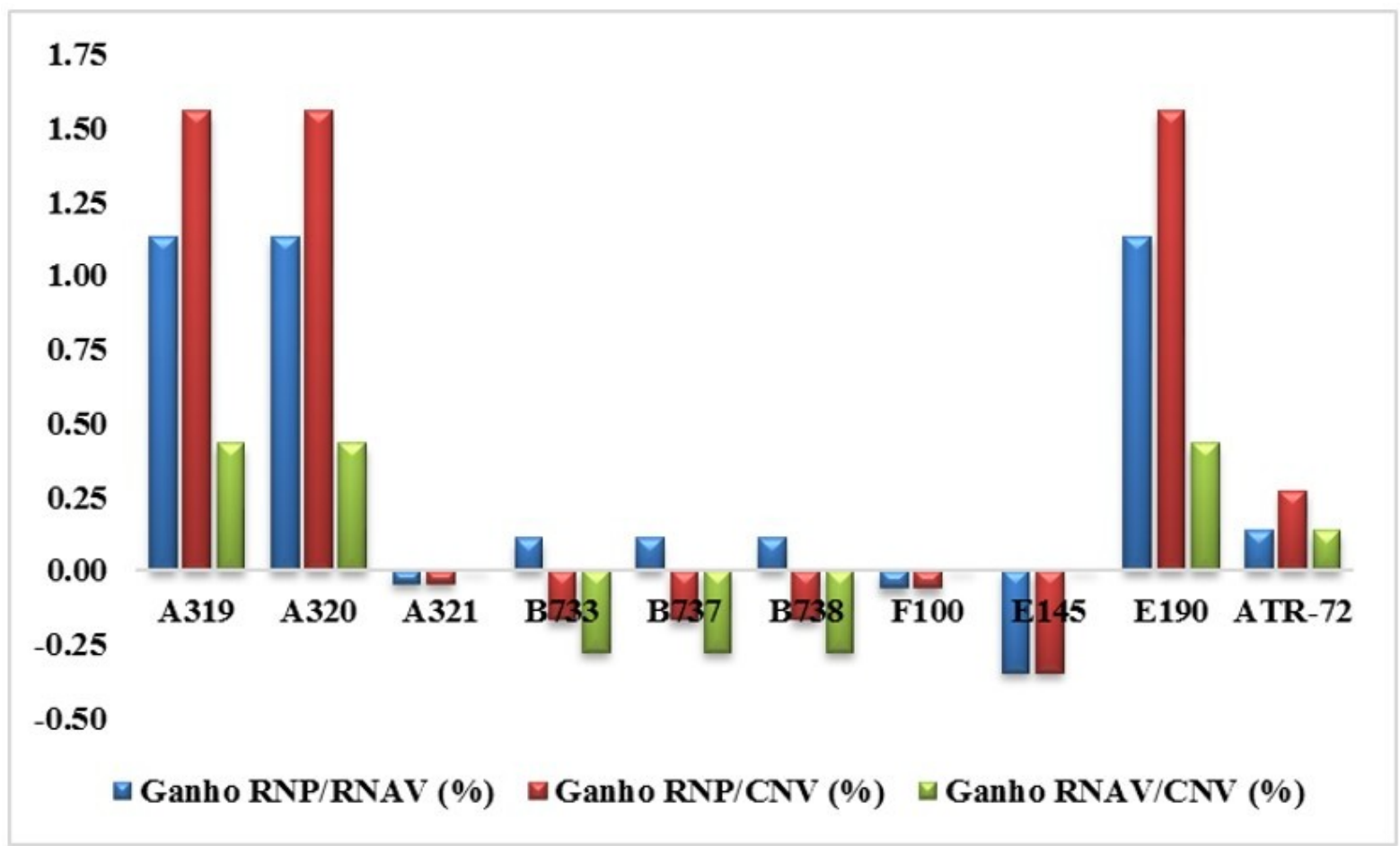

Figura 13. Ganho total em percentagem da rota entre procedimentos Fonte: Próprio autor

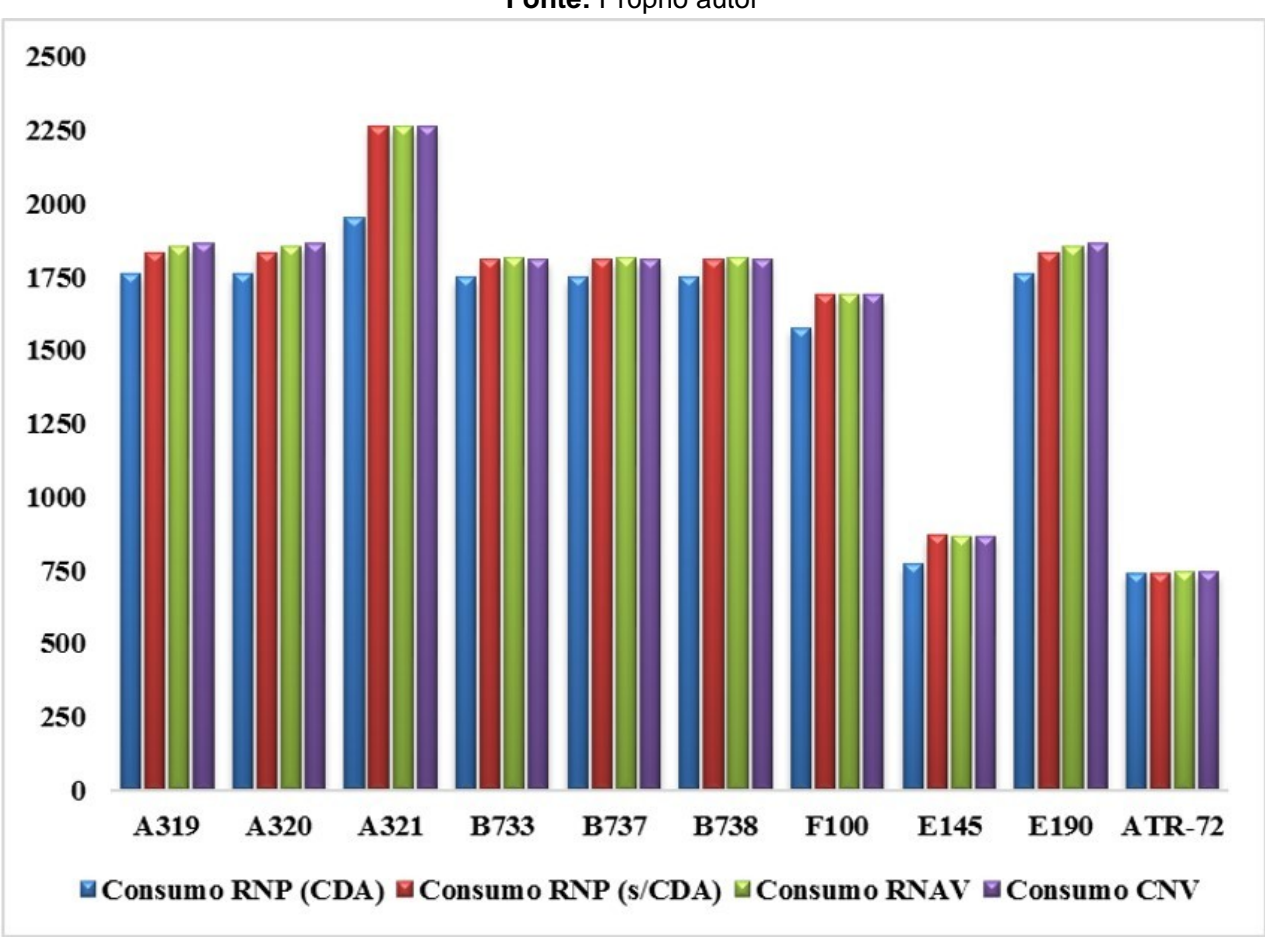

Figura 14. Consumo total da rota em quilos por procedimento RNP com CDA e sem CDA Fonte: Próprio autor

aeronave utiliza a técnica de CDA, ela voa na altitude de cruzeiro por um maior tempo até atingir o ponto ideal para a realização de uma descida otimizada, utilizando o mínimo possível de potência.

Para simular o CDA, o TAAM realiza cálculos para manter a continuidade da descida e seguir as restrições de altitude previstas no procedimento de chegada (STAR). Pode ocorrer de a aeronave ter que manter o voo nivelado por um curto período de tempo para cumprir as limitações impostas. Essa sistemática é seguida em todos os pontos do procedimento.
O TAAM permite que alguns parâmetros de voo, como peso máximo de decolagem, velocidades de decolagem, ponto de início de descida, entre outros possam ser “aleatorizados”, buscando simular a utilização de aeronaves por vários tipos de pilotos que possuem diferenças em suas técnicas de pilotagem. A função de aleatoriedade foi desabilitada no estudo, buscando simular que a mesma técnica de pilotagem seja utilizada para comparar as rotas voadas.

\section{RESULTADOS}

Os resultados mostram que cada aeronave possui um consumo de combustível associado à execução dos perfis 


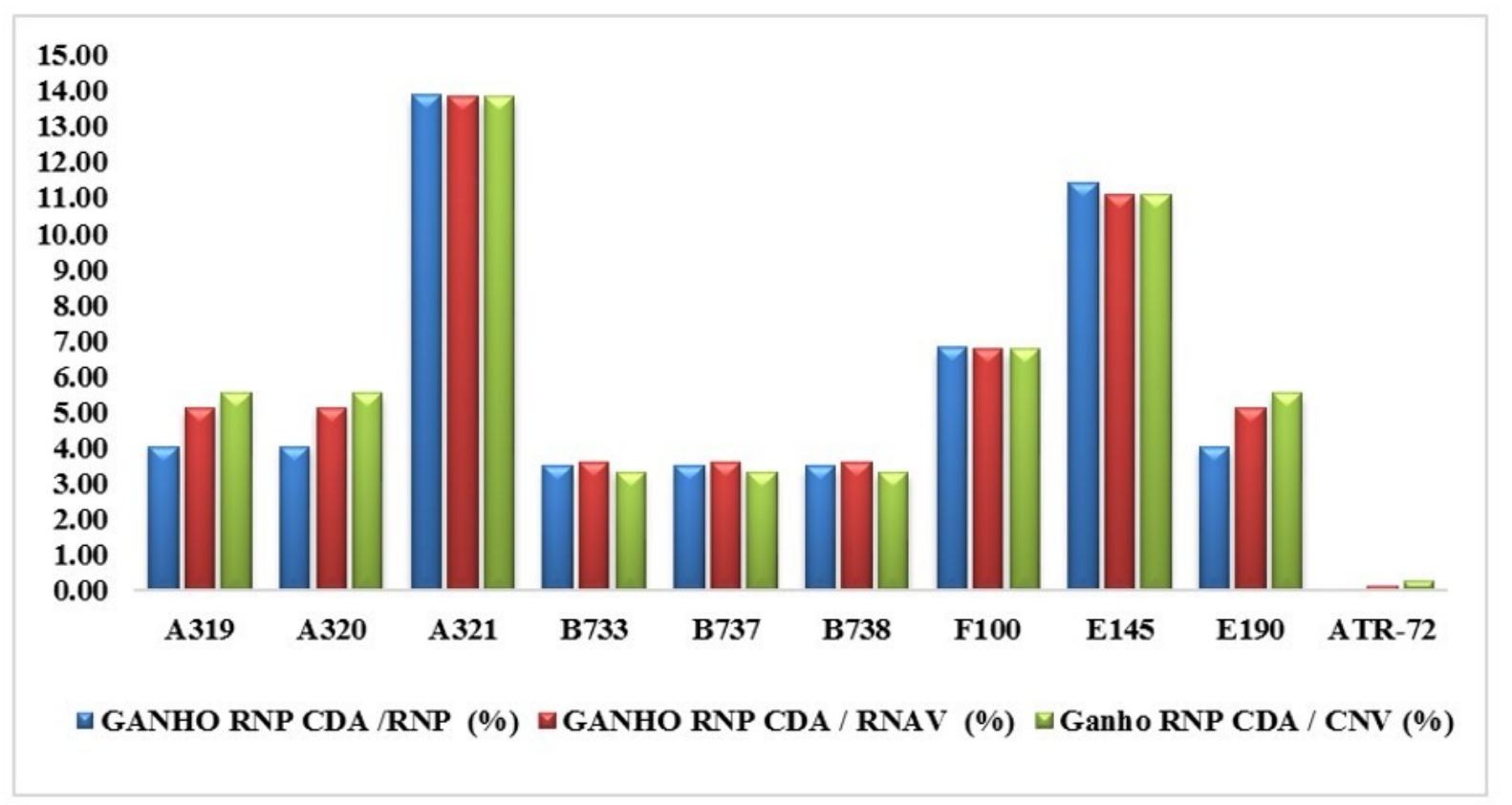

Figura 15. Ganho total em rota em percentuais de procedimento RNP com CDA e sem CDA

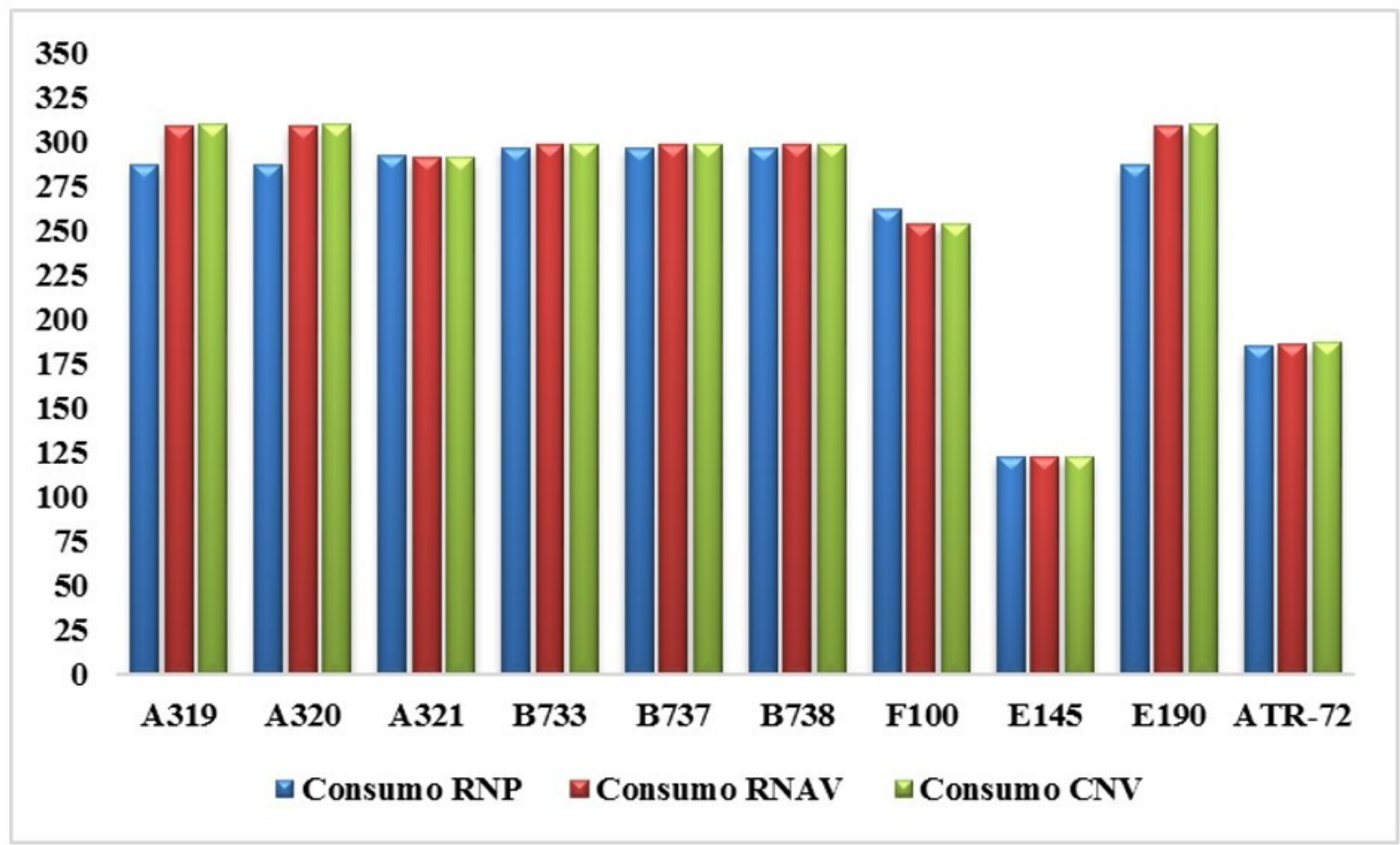

Figura 16. Consumo total em quilos por procedimento sem CDA

Fonte: Próprio autor

dos procedimentos. Para fins de análise, o consumo de combustível será analisado em termos de consumo em toda rota e consumo durante o procedimento de aproximação e pouso. Os resultados do consumo (output da simulação) são em quilos de querosene de aviação (JET A-1).

Para saber, em percentuais, qual a economia pela realização de determinado procedimento em comparação com outro utilizou-se a métrica de ganho. $\mathrm{O}$ ganho $\mathrm{X} / \mathrm{Y}$ representa a economia, em percentuais, do consumo de combustível na realização do procedimento $X$ quando comparado com a realização do procedimento Y. Para efeitos de análise foram comparados os procedimentos RNP, RNAV e Convencional (CNV). Os ganhos positivos ocorrem quando a realização do procedimento $\mathrm{X}$ é mais benéfica quando com- parado com o procedimento $\mathrm{Y}$ e a negativa quando o consumo do procedimento Y é menor quando comparado com o procedimento X. A ausência de representação significa que não houve diferença no consumo de combustível na realização dos diferentes procedimentos.

\subsection{Consumo total na rota}

O consumo das aeronaves em rota mostra que a realização dos procedimentos RNP e RNAV apresentam consumos muito próximos, sendo que para o A321, F100 e E145 a utilização do procedimento RNP quando comparado com o RNAV apresentou maior consumo, com uma diferença máxima de quatro quilos. O consumo total por tipo de 


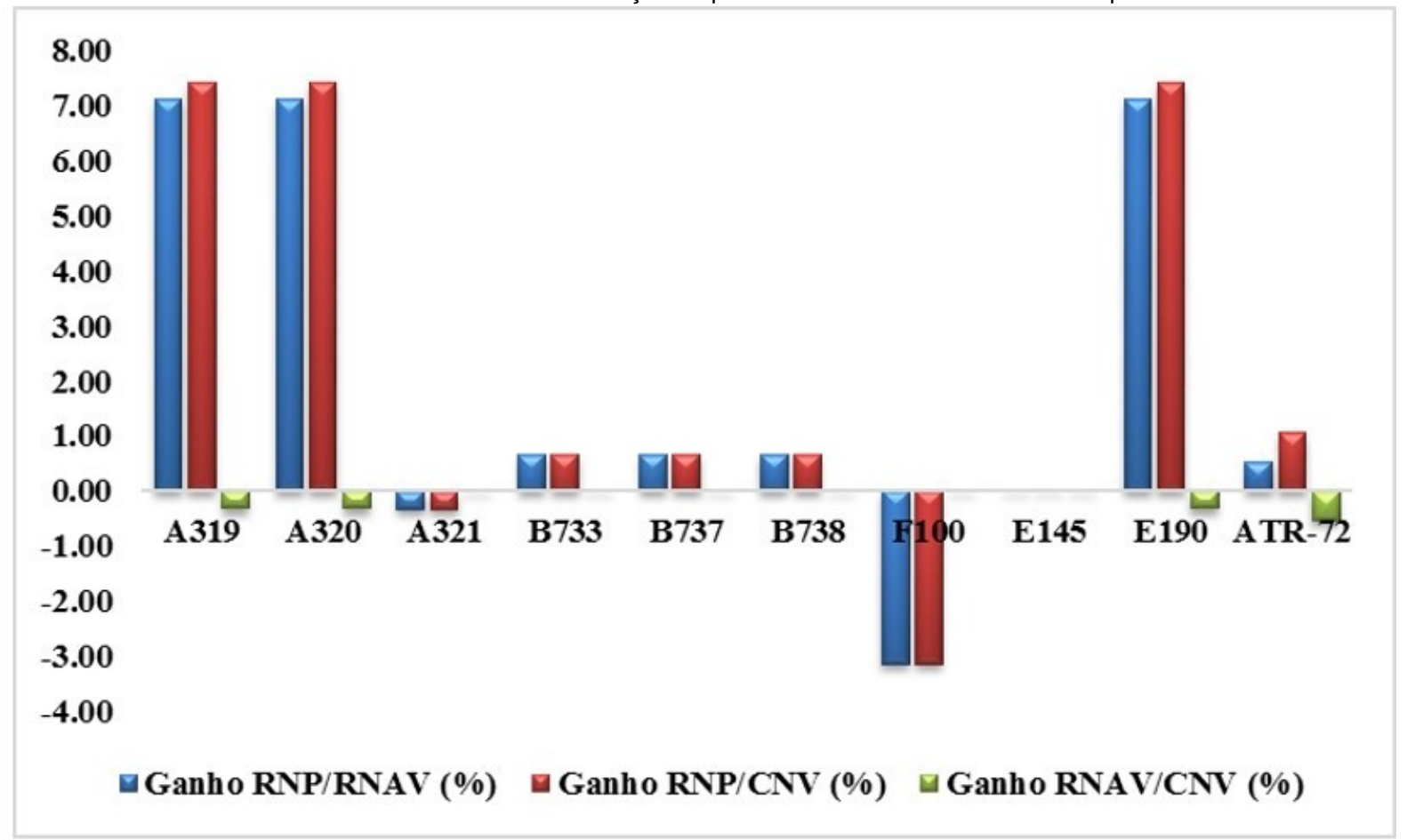

Figura 17. Ganho de consumo em percentagem por procedimentos sem CDA Fonte: Próprio autor

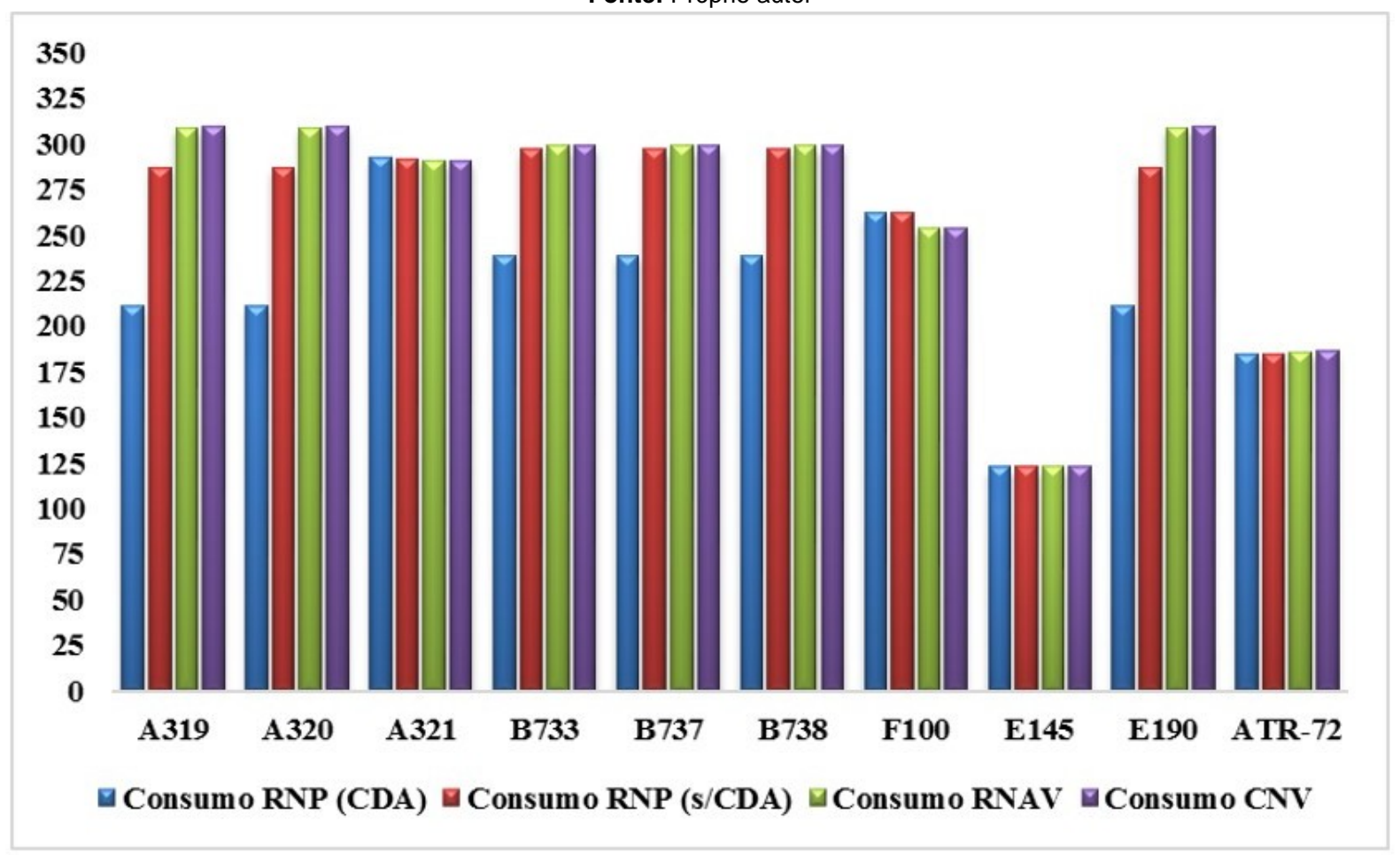

Figura 18. Consumo total em quilos por procedimento RNP com CDA e demais sem CDA Fonte: Próprio autor

procedimento sem a utilização de CDA está representado na Figura 12.

Os consumos apresentados entre uma aeronave voando um procedimento RNAV e Convencional (CNV) são parecidos pois analisando o perfil lateral e vertical da rota voada, o único ponto de diferenciação dos dois procedimentos é a restrição das aeronaves passarem, quando da execução do procedimento ILS, a 4.060 pés no ponto GR036 e quando as aeronaves executam o RNAV, a restrição é de 4.100 pés ou mais no mesmo ponto. Inferências podem ser realizadas no sentido que devido às aeronaves que executaram a rota RNAV passarem mais tempo voando em regime de cruzeiro, o que impactou em diferenças de consumo entre rotas RNAV e CNV. Porém, a diferença máxima foi de, no máximo, $8 \mathrm{~kg}$, o que representa menos de 0,4\% do total consumido na rota.

Os ganhos por tipo de procedimento voado encontram-se na Figura 13. Os ganhos apresentados foram diferentes por modelo de aeronave. Os ganhos do RNP quando comparado com o RNAV foram de $-0,35 \%$ a $1,13 \%$. As aeronaves A319, A320 e E190 apresentaram o melhor desempenho, ao passo que para o A321, F100 e E145 a realização do RNAV foi mais benéfica. Apenas para os modelos A319, A320, E190 e ATR-72 foi mais benéfica a realização do RNP quando comparado com o Convencional, porém com 


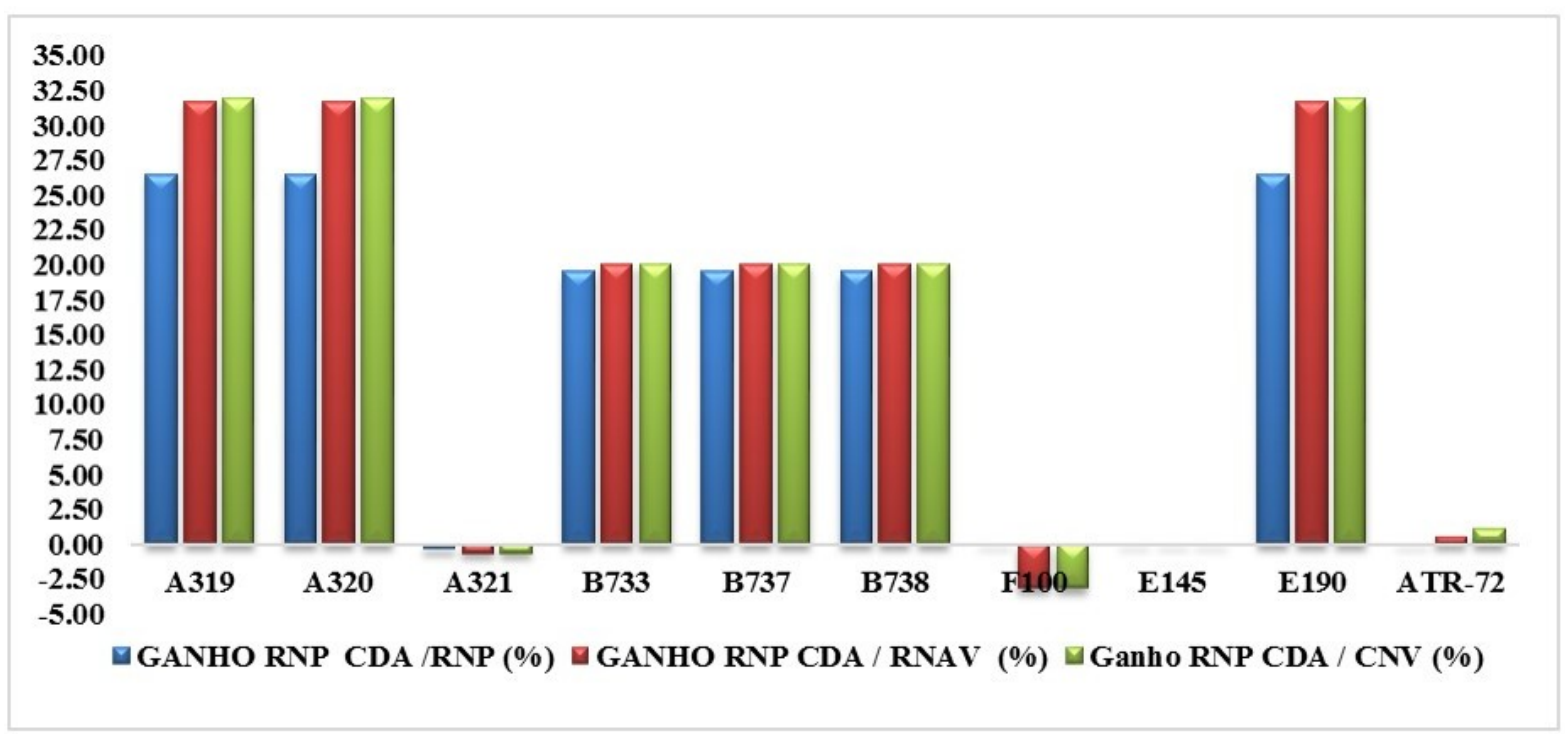

Figura 19. Ganho de consumo em percentagem por procedimentos RNP / CDA e demais procedimentos Fonte: Próprio autor

uma mínima diferença de consumo. Para o A321, F100 e E145 não houve diferença de desempenho na realização do RNAV e Convencional.

A utilização da técnica de descida contínua (CDA) gerou um menor consumo de combustível. Ao permitir que o ponto de início da descida seja postergado, a aeronave voou mais tempo em cruzeiro e realizou os perfis de descida com pouca utilização de motor. O consumo total de combustível com a utilização do RNP e aplicação da técnica de CDA mostrou-se menor quando comparado com a utilização do RNP, RNAV e Convencional, com uma economia de até $13 \%$ (A321). A aeronave ATR-72, por ser um turboélice e voar uma altitude de cruzeiro mais baixa (18.000 pés) não apresentou ganhos com a utilização da técnica de CDA quando comparado entre a realização do RNP. A Figura 14 mostra o consumo total no procedimento RNP com a utilização do CDA e nos demais procedimentos sem CDA.

Os ganhos com a utilização do CDA estão representados na Figura 15. Para todos os modelos houve economia de combustível quando da realização do RNP com o CDA, apresentando ganhos de até 13,83\% (A321) quando comparado com o Convencional. As demais aeronaves apresentaram ganhos de 11,10\% (E145); 5,53\% (A319 e A320) e 3,32\% (B733, B737 e B738).

\subsection{Consumo total por procedimento de chegada e pouso}

A Figura 16 mostra o consumo quando analisado apenas o procedimento de chegada (STAR) e pouso (IAC). Para efeitos de cálculo, o consumo é calculado a partir do primeiro ponto da STAR até a parada da aeronave na pista, sendo desabilitada a função de taxi até o pátio de estacionamento.

Analisando o consumo de combustível na realização do procedimento de aproximação (STAR mais IAC) as aeronaves A319, A320 e E190 apresentaram a maior economia de combustível (13kg) com a realização de procedimentos RNP, os demais modelos apresentaram economia máxima de 2 quilos. O E145 apresentou o mesmo consumo para os três tipos de procedimento. O A321 e F100 apresentaram um melhor desempenho na realização do RNAV ou
Convencional. Quando a comparação foi entre rotas RNAV e Convencional, os resultados ficaram muito próximos, com uma diferença máxima de $1 \mathrm{~kg}$.

Os ganhos operacionais estão representados na Figura 17.

Cada modelo de aeronave apresentou, para a rota estudada, um desempenho específico. A maior economia com a realização do RNP foi das aeronaves A319, A320 e E190 com $7,12 \%$ comparado com o RNAV e 7,42\% comparado com o CNV. O F100 não apresentou melhora de consumo com a realização do RNP. O ganho do RNAV em comparação com o Convencional ficou entre $-0,54 \%$ a $0 \%$ mostrando pouca diferença no tipo de procedimento realizado.

O consumo do procedimento RNP com CDA e os demais procedimentos estão representados na Figura 18. O A319, A320 e E190 apresentaram economia de $90 \mathrm{~kg}$ e o B733, B737 e B738 de $60 \mathrm{~kg}$ quando comparados com a realização do Convencional.

Os ganhos com a utilização do CDA estão indicados na Figura 19.

As aeronaves A319, A320 e E190 apresentaram uma economia de até 32\% quando comparado com o Convencional. As aeronaves B733, 737 e 738 apresentaram economia de $20,07 \%$. As aeronaves F100, E145 e ATR72 não apresentaram economia de combustível com a utilização da técnica CDA.

\section{CONSIDERAÇÕES FINAIS}

O constante uso da aeronave como meio de transporte trouxe a necessidade de inserir novos meios de navegação e utilização do espaço aéreo. Os procedimentos PBN trouxeram mudanças fundamentais na operação das aeronaves, nos procedimentos dos pilotos e na introdução de novos equipamentos embarcados nas aeronaves. Sua implementação é considerada fundamental para os programas de modernização do transporte aéreo.

Várias pesquisas têm sido realizadas para verificar a eficiência da utilização de procedimentos PBN nos aeroportos. A implantação do conceito no Brasil, em especial no eixo de Rio-São Paulo no final de 2013, trouxe a necessidade de analisar e verificar os ganhos advindos com a sua 
Análise dos benefícios da utilização de procedimentos baseados em desempenho e

da utilização de aproximações de descida contínua na rota Galeão-Guarulhos

utilização. O estudo atual, ao utilizar como base a rota Galeão - Guarulhos e análise dos procedimentos de chegada e pouso nessa rota mostraram que o desempenho e a economia de combustíveis estão diretamente ligados ao perfil do procedimento e características da aeronave. Dependendo do tipo de procedimento e da aeronave, economias na ordem de $30 \%$ são verificadas, o que condiz com estudos realizados em outras partes do mundo.

A introdução de novas técnicas de utilização do espaço aérea traz ao pesquisador da área de transporte aéreo novos desafios para a verificação de sua eficácia. Os resultados obtidos nesse estudo não devem ser vistos de forma determinística, mas sim como indicadores para análise. Deve-se sempre ter em mente, que um modelo de simulação é uma simplificação da realidade e que nas situações reais outros fatores exercem influência. A simulação em tempo acelerado mostrou-se útil para a análise de um conceito de navegação e a quantificação de custos.

Novos cenários deverão ser analisados comparando o consumo de combustível na realização de procedimentos PBN em outros aeroportos, assim como a verificação dos níveis de consumo quando da interação de tráfego aéreo, com várias aeronaves chegando e partindo de um aeroporto. Da mesma maneira, estudos futuros deverão comparar os ganhos de combustível com a utilização do PBN em outras rotas. Outros estudos poderão verificar se os ganhos operacionais obtidos quando as aeronaves estiverem voando de forma isolada serão mantidos quando as aeronaves estiverem em uma situação normal de tráfego aéreo, com a interação de outras aeronaves voando para os mais variados destinos.

Em um ambiente marcado pela competição das empresas aéreas e constante procura por maneiras lucrativas e seguras de operação, a busca por procedimentos mais econômicos é uma necessidade. A verificação de qual procedimento melhor se adequa a frota e a malha aérea é essencial para a sobrevivência e continuidade das empresas do transporte aéreo.

\section{REFERÊNCIAS}

ANAC - Agência Nacional de Aviação Civil. Anuário Estatístico do Transporte Aéreo (2013). Dados Estatísticos e Econômicos de 2012. Brasília.

Banks, J. Handbook of simulation. Wiley Online Library, 1998. dx.doi.org/10.1002/9780470172445

Chandra, D. C.; Grayhem, R.; Butchibabu, A. Area Navigation and Required Navigation Performance Procedures and Depictions. Volpe Institute. 2012.

DECEA - Departamento de Controle do Espaço Aéreo (2013). Cartas de procedimento de voo por instrumento. Brasil.

ICAO- International Civil Aviation Organization (2013). Doc 9613. Performance-Based Navigation (PBN) Manual. 4th Edition. Quebec, Canada.

ICAO- International Civil Aviation Organization (2010). Doc 9931.Continuous Descent Operation (CDO). 1th Edition. Quebec, Canada

ICAO. International Civil Aviation Organization (2006). Doc 8168. Procedures for Air Navigation Services, Aircraft
Operations, PANS-OPS, Volume II, Construction of Visual and Instrument Flight Procedures. 5th Edition. Quebec, Canada.

Muller, D.; Uday, P.; Marais, K. B. (2011). Evaluation of the potential environmental benefits of RNAV/RNP arrival procedures. 11th AIAA ATIO conference Virginia. dx.doi.org/10.2514/6.2011-6932

Nolan, M. S (2010). Fundamentals of air traffic control. Cengage Learning.

Pidd, M. (1994). An introduction to computer simulation. Proceedings of the 26th conference on Winter simulation. dx.doi.org/10.1109/WSC.1994.717064

Sprong, K. R. (2005). Measuring the effects of RNAV departure procedures on airport efficiency. Digital Avionics Systems Conference. dx.doi.org/10.1109/DASC.2005.1563329

Sprong, K. R. et al. (2005) Improving flight efficiency through terminal area RNAV. 6th USA/Europe Air Traffic Management $R \& D$ Seminar.

Sprong, K. R.; Mayer, R. H. (2007). Analysis of RNAV arrival operations with descend via clearances at Phoenix Airport. 26th IEEE/AIAA Digital Avionics Systems Conference. dx.doi.org/10.1109/dasc.2007.4391874

White JR, K. P.; Ingalls, R. G. (2009). Introduction to simu lation. Winter Simulation Conference. dx.doi.org/10.1109/wsc.2009.5429315 